\title{
LA OPOSICIÓN AL RÉGIMEN FRANQUISTA EN BARCELONA. ALGUNAS MUESTRAS ENTRE 1948 Y 1951
}

\author{
por
}

\section{Mercedes VÁZQUeZ de Prada}

Universidad de Navarra

RESUMEN: El artículo se refiere a la situación económica y político-social de Cataluña, especialmente de la ciudad de Barcelona, durante el primer franquismo. Se describen algunas muestras de la oposición general a la política del régimen, durante dicha etapa, que desembocó en la buelga general de marzo de 1951.

En primer lugar, se expone la posición de los empresarios de la industria textil catalana ante la deteriorada situación económica y social de finales de los años cuarenta. A continuación se plantea la oposición a la política de partido único reflejada en las primeras elecciones municipales de noviembre de 1948, desarrolladas en medio de una gran abstención.

Finalmente, se abordan el viaje de Franco a Barcelona para tratar sobre el terreno la crisis económica, recibido con frialdad por la sociedad catalana, y la buelga general de marzo de 1951 que señaló el punto álgido de la crisis vivida en la sociedad catalana y el inicio de un cambio de rumbo por parte del Gobierno. Las fuentes utilizadas para la realización de la investigación provienen del archivo del conde de Fontanar.

Palabras clave: Primer franquismo. Cataluña. Oposición política. Industria textil. Elecciones municipales. Huelga de 1951.

ABSTRACT: This article reviews the sociopolitical and economical situation of Catalonia during the first years of Francoism, specially in Barcelona. It shows some examples of oposition against this regime, which led to the general strike of. March, 1951.

First of all, it studies the position of the textile industry businessmen and the economical and social situation at the late forties. It analyze the opposition to a «single party» politics in the first local elections of November, 1948, and the bigh abstention. It shows that the visit of Franco to Barcelona in an atmosphere of economical crisis failed to gain support for bis regime. 
Finally, it explains how the general strike of March, 1951, marked a turning point in the crisis and it provoked a change in the policies of the government. The sources used in this research belong to the archives of the count of Fontanar.

KEY WORDS: Early francoism. Catalonia. Political opposition. Textile industry. Local elections. General strike of 1951.

\section{INTRODUCCIÓN}

En general, la historia social sobre la etapa del primer franquismo carece todavía de estudios sólidos de conjunto y de síntesis concluyentes. No obstante, existen importantes investigaciones regionales, y son las referidas a las denominadas regiones históricas las que han recibido mayor atención por parte de los historiadores ${ }^{1}$.

La perspectiva regional y local permite observar cómo se llevaron a la práctica y el efecto que tuvieron las medidas adoptadas a nivel nacional por el régimen. Como ha señalado Nicolás Marín², la investigación de los mecanismos de acción política, la extracción de recursos, las relaciones sociales o las sensibilidades económicas deben ser estudiadas en las comunidades locales.

El presente artículo trata sobre algunos aspectos de la oposición a la política del régimen franquista en Cataluña y, especialmente, en la ciudad de Barcelona durante los años finales de la posguerra. Cataluña, avanzada económica y social del país, fue una de las zonas en las que primero se organizó la oposición política y social al régimen, en un momento especialmente crítico para su asentamiento y desarrollo ${ }^{3}$. Las muestras de oposición socioeconómica y política catalana permiten profundizar sobre la política del régimen, y la situación española en general durante la referida época ${ }^{4}$.

Las fuentes utilizadas para la realización de este trabajo propuesto son documentos e informes depositados en el archivo de Francisco Carvajal y Xifré, conde de Fontanar, que fue secretario político del Consejo de Acción Monár-

1 Entre las más recientes, para Castilla-León, por ejemplo, la de MARTín JimÉnEz, Ignacio, La posguerra en Valladolid (1939-1950, Valladolid, Ámbito, 2002.

2 NiCOLÁs MARín, Encarna, «Los poderes locales y la consolidación de la dictadura franquista», en SÁnChez ReCio, Glicerio, (ed.), «El Primer Franquismo (1936-1959)», Ayer, núm. 33, Madrid, 1999, p. 64-85 y MARTíNEZ RUEDA, Fernando, "Algunes consideracions sobre l'estat actual de la història local», en Afers, núm. 27, 1997, pp. 675- 699.

3 Sobre las actitudes y la situación general en Cataluña véase RuQueR, Borja. de, «Rebuig, passivitat i suport. Actituds politiques catalanes davant el primer franquisme (1939-1950)» en VV. AA., Estudios sobre Historia de España, vol. 2, Madrid, UIMP, 1981.

4 Nicolás MARíN, Encarna, "Conflicto y consenso en la historiografía de la dictadura franquista: una historia social por hacer", en IV Jornadas de Historia y Fuentes Orales: Historia y memoria del franquismo (1936-1978), Ávila, 1997, pp. 27-38. 
quica desde $1946^{5}$. Dichos documentos, que proceden del grupo monárquico catalán, ilustran sobre la postura de los industriales textiles catalanes ante el conflicto sociolaboral y sobre el clima de oposición manifestado por las primeras elecciones locales de 1948, por la frialdad del recibimiento a Franco en su viaje a Barcelona, en 1949, y por la huelga general de 1951.

\section{LOS INDUSTRIALES CATALANES ANTE EL CONFLICTO SOCIOLABORAL DE FINALES DE LOS AÑOS CUARENTA}

La década de los cuarenta estuvo marcada por la inflación, el proteccionismo, el intervencionismo estatal y la sobrevaloración de la peseta. Esta situación supuso, como es sabido, una notable pérdida de competitividad en los mercados internacionales y un descenso general de las exportaciones ${ }^{6}$. Además, estos años fueron muy duros para el conjunto de la población por el racionamiento de los alimentos que duró hasta $1952^{7}$, y por las condiciones de vida y de trabajo. De hecho, el alza de los precios y la devaluación de los salarios motivaron las primeras huelgas entre 1946 y $1952^{8}$.

La política económica del primer franquismo fracasó absolutamente, ya que ni siquiera consiguió recuperar las magnitudes económicas anteriores a la guerra civil. Esta política tuvo como premisa fundamental conseguir la autarquía a través de la creación de una sólida capacidad productora que sustituyera las importaciones. El proceso de industrialización se apoyó por ello, básicamente, en la potenciación de las industrias pesadas, la mayor parte de las cuales fueron declaradas de interés nacional y gozaron de privilegios legales y de diversas preferencias, en el suministro de maquinaria, de materiales de construcción o de materias primas, que el Gobierno concedió discrecionalmente9. Tal plan-

El Consejo tenía como función coordinar y dirigir la actividad monárquica en el interior.

6 Véase París EguIlaz, Higinio, Diez años de política económica en España: 1939-1949, Madrid, 1949 p. 85 y ss. No obstante, el comercio exterior fue intenso con algunos países como Gran Bretaña, véase al respecto VIÑAS, Ángel et al., Política comercial exterior de España (1931-1975), vol. I, Madrid, Banco Exterior, 1979, p. 571.

7 Sobre el mercado negro y el racionamiento de alimentos véase BARCIELA, Carlos., «El mercado negro de productos agrarios en la posguerra, 1939-1953", en FONTANA, Josep, España bajo el franquismo, Barcelona, Crítica, 1986; «La España del estraperlo», en GARCíA DELGADO, José Luis, (ed.), El primer franquismo. España y la Segunda Guerra Mundial, Madrid, Siglo XXI, 1989, pp. 105121, y AlBURQuerQue, Francisco, «Métodos de control político de la población civil: el sistema de racionamiento de alimentos y productos básicos impuestos en España tras la Guerra Civil», en VV. AA., Estudios sobre Historia de España, op. cit.

8 Véase al respecto FERRI, Llibert, MUIXI, Jordi y SANJUAN, Eduardo, Las buelgas contra Franco (1939-1956), Barcelona, Planeta, 1978.

9 Véase BALlestero, Alfonso, Juan Antonio Suanzes, 1891-1977. La politica industrial de la posguerra, León, 1993; THOMAS, Joan María, José Maria Fontana Tarrats. Biografía política d'un franquis- 
teamiento implicó la subordinación del resto de los sectores económicos a las necesidades de la industria básica.

Cataluña sufrió de manera muy notable la crisis económica de la posguerra. La producción industrial, el sector fundamental de la economía catalana, sólo experimentó un aumento de 6,6 enteros, mientras la producción agrícola bajó 26,8 enteros. El comercio exterior sufrió igualmente un descenso notabilísimo. ${ }^{10}$ Es preciso tener en cuenta a este respecto que la industria textil resultó particularmente perjudicada por la política del régimen. Una política que primó a la industria pesada sobre la de bienes de consumo y que tuvo, por su anticatalanismo, un carácter discriminatorio en la asignación de «cupos» de materias primas, instalación de nuevas centrales eléctricas, etc. ${ }^{11}$

Los industriales catalanes, en general, acogieron con satisfacción a un régimen que restauró el orden social y les devolvió sus propiedades. La patronal catalana conservó durante el franquismo sus organizaciones corporativas. Su obligada incorporación al Sindicato Vertical no supuso ninguna desarticulación, ya que estuvieron plenamente representadas en los organismos de dirección económica del mismo ${ }^{12}$.

A pesar de que los mecanismos económicos se hallaban alejados de los centros sindicales, los empresarios utilizaron la burocracia verticalista para obtener privilegios y tratos de favor en el reparto de materias primas, energía o licencias de importación y, en ocasiones, para ejercer presión para conseguir cambios en la política económica del Gobierno ${ }^{13}$. Se trata éste de un aspecto que ha sido poco estudiado, pero parece que algunas delegaciones sindicales se convirtieron en centros de discusión del intervencionismo estatal y de crítica moderada al Estado para lograr cambios parciales en la política económica.

Especialmente las Cámaras de Comercio e Industria realizaron una importante labor de asesoramiento mediante la elaboración de informes sobre la situación económica y las posibles soluciones de la crisis, entre las que se planteaba claramente la rectificación de la política autárquica.

La postura de los industriales textiles catalanes, a quienes el ordenancismo económico resultaba especialmente perjudicial (ya que dependían de las impor-

\footnotetext{
ta catalá, Reus, 1997, y CATALÁN, J., La economía española y la Segunda Guerra Mundial, Barcelona, Ariel, 1995.

10 Sobre la relación entre política económica y trayectoria del mercado exterior véase VIÑAS, Ángel et al, Política comercial exterior de España (1931-1975), vol. I, p. 571 y ss., Madrid, Banco Exterior de España, 1979.

11 Véase PALOMERo MARTíneZ, Dora., Los trabajadores de ENASA durante el franquismo, Barcelona, Sirius, Memoria Histórica, 1996, p. 36.

12 RAMOS, Gemma, «El sindicat vertical: mecanisme de control social o instrumento de poder», en Franquisme, Barcelona, Crítica, 1990.

13 Barciela, Carlos, «Franquismo y corrupción económica», en Historia Social, $\mathrm{n}^{\circ} 30,1998$, pp. 83-96, y DíEz CANO, Luis S., Las Cámaras de Comercio en el franquismo, Salamanca, 1992.
} 
taciones de materias primas, energía y maquinaria), muestra una clara crítica al intervencionismo y, en general, a la política económica del régimen ${ }^{14}$.

En asamblea celebrada el 13 de septiembre de 1949, la Cámara Oficial de Industria de Barcelona confió a una ponencia ${ }^{15}$ la tarea de estudiar la situación económico-social de la industria textil en general ${ }^{16} \mathrm{y}$ de la algodonera en particular. El objetivo era fijar la posición de la Industria ante la demanda general y acuciante de un aumento de los salarios.

$\mathrm{Al}$ exponer los problemas y señalar sus posibles causas, la ponencia refleja el malestar generalizado de ese sector tan relevante de la burguesía empresarial de Cataluña, así como una franca discrepancia con respecto a la política oficial.

Los industriales denuncian que, desde el último trimestre de 1948, la realidad socioeconómica había cambiado. La depresión económica se había acentuado de tal modo que la curva descendente de la producción no pudo ser contenida. El mercado negro lograba suplir ya totalmente el déficit del racionamiento oficial. Los negocios fáciles habían sido eliminados, el consumo de productos industriales caía verticalmente y el obrero ya no podía recurrir a aquellos factores que le habían permitido suplir la baja del valor adquisitivo de los salarios. El fantasma trágico de la miseria comenzó a amenazar a los hogares.

\section{El aumento de la inflación y la carestía de la vida}

En primer lugar, los industriales señalan el aumento de la inflación. Desde el fin de la guerra existió una gran desproporción entre los salarios oficiales y el coste de la vida que siguió aumentando progresivamente ${ }^{17}$. Según los datos oficiales facilitados por el Instituto Nacional de Estadística del año 48-49, el valor adquisitivo del salario en 1948 comparado con el de 1936 representaba aproximadamente el $50 \%$.

Tal disminución sólo hubiera sido sostenible, y por poco tiempo, en opinión de los industriales, si el racionamiento oficial de artículos alimenticios de pri-

14 Sobre el reparto de materias primas en la industria véase RiBAS, Antoni., L'Economía Catalana sota el franquisme (1939-1953), Barcelona, 1978, y en general, TORTELLA, Gabriel, El desarrollo de la España contemporánea. Historia económica de los siglos XIX y XX, Madrid, Alianza, 1994. Sobre la postura de los industriales catalanes véase MOLINERO, Carme e YSÁS, Père, Els industrials catalans durant el franquisme, Vic, Eumo, 1991.

15 Ponencia de la Industria catalana sobre la situación de la industria textil, octubre de 1949. Archivo Conde de Fontanar. Archivo Histórico, Universidad de Navarra. Sin paginar.

16 Sobre la postura general de los empresarios véase también, YSÁS, Pere, «Los empresarios catalanes en el primer franquismo, en SÁNCHEZ ReCiO, Glicerio y TASCón FerNÁNDEZ, Julio (eds.), Los empresarios de Franco: Política y Economía en España (1936-1957), Barcelona, Crítica, 2003.

17 Ibid. ponencia de la Industria de 1949. Véase también MOLINERO, Carme e YSÁS, Père, «Patria, justicia y pan». Nivell de vida y condicions de treball a Catalunya 1939-1951, Barcelona, La Magrana, 1985, y SUDRIÁ, Carles, «Una societat plenament industrial», en Història Econòmica de la Catalunya Contemporània, vol. IV. 
mera necesidad hubiera resultado suficiente. Pero las cifras demostraban que tal racionamiento no sólo era insuficiente, sino muy escaso. Los productos alimenticios básicos del racionamiento oficial, facilitados a la población obrera a precios legales, no llegaban a cubrir el $25 \%$ de sus necesidades mínimas ${ }^{18}$.

En la ciudad de Barcelona y su cinturón, que tuvieron un racionamiento privilegiado en 1948, resultaba que para alcanzar el suministro que prometió la orden de 14 de marzo de 1939, el trabajador tenía que adquirir en el mercado negro, para él y para cada uno de los miembros de su familia, un mínimo mensual de 7 kilos de pan, 1,250 de bacalao, 12,750 de legumbres y 0,600 de azúcar. Todos los artículos citados estaban rigurosamente controlados, pero en el mercado negro aparecían unas cantidades muy superiores a las que suministraban las Comisarías de Abastos. De modo que se adquirían los productos a precios entre un 300 y un 600 por ciento más altos.

El fracaso del sistema intervencionista de los alimentos básicos y la distribución insuficiente de tales artículos por los organismos creados al efecto habían constituido el más poderoso aliciente para el desarrollo del mercado negro.

Según explica el informe de la Industria de Cataluña ${ }^{19}$, el intenso y prolongado paro provocado por las restricciones eléctricas dio lugar a que la mayor parte de la población obrera, que no podía ser absorbida por las actividades industriales no afectadas por las expresadas causas de paro, afluyera a la casi interminable cadena de intermediarios del mercado negro. El mercado negro adquirió, de esta forma, un auge extraordinario. "Utilizando todos los medios de transporte a su alcance, la población obrera en paro subsidiario se trasladaba diariamente de la ciudad al campo, para regresar con artículos y alimentos que vendían en el mercado negro, buscando en las diferencias de precio el complemento que precisaba para sus necesidades. Claro que este proceso, aparentemente complicado, pero en realidad lógico y sencillo, hurtaba al mercado legal cada día mayor cantidad de mercancías que afluían al mercado negro, y por otro lado iba elevando gradualmente los precios».

Además, los trabajadores conseguían el complemento vital de su alimentación porque las propias empresas acudieron a paliar, en la medida de sus posibilidades, la notoria insuficiencia de los jornales mediante la concesión de pluses transitorios, suministros en especie, etc.

\section{Las restricciones eléctricas}

En segundo lugar, los industriales tratan sobre el gravísimo problema de la restricción eléctrica. Según los datos disponibles, las restricciones eléctricas

\footnotetext{
18 Sobre el empeoramiento general de los niveles de vida obreros y populares véase MORADIELLOS, Enrique, La España de Franco (1939-1975). Política y sociedad. Madrid, Síntesis, 2000, pp. 88-89.

19 Ponencia de la Industria Catalana sobre la situación de la Industria textil, octubre de 1949. Archivo Conde de Fontanar. Archivo Histórico, Universidad de Navarra. Sin paginar.
}

Hispania, LXIII/3, núm. 215 (2003) 1057-1078 
desde el 15 de septiembre de 1948 hasta 1949, fueron alarmantes en la zona catalana. Se ha calculado que en la industria textil no se pudo trabajar durante la década de los cuarenta el equivalente a una cuarta parte del tiempo de trabajo. La falta, cada día más acentuada, de energía eléctrica implicó el descenso de la producción y el encarecimiento de la misma. En opinión de los empresarios textiles, aunque el colapso no se había producido hasta entonces, la amenaza del mismo se veía cada vez más próxima.

(...) Las restricciones eléctricas obligaban a la industria a hacer uso de viejos motores, de gas pobre, etc., con rendimiento muy bajo, de funcionamiento muy irregular y de alimentación muy cara. Consecuencia lógica de todo ello ha sido un encarecimiento de la producción, y como en el último año ese encarecimiento ha coincidido, por las circunstancias antes citadas, con una restricción creciente de la capacidad de absorción del mercado interior, la demanda ha descendido y han empezado a formarse stocks de mercancías que no podían ser absorbidas, la crisis industrial se acentúa y el fantasma del paro inicia su aparición» ${ }^{20}$.

En el aspecto económico-social el problema de la escasez de energía era según los industriales aún más acuciante, ya que trascendía a la calle. Al principio se había creado un subsidio especial por escasez de fluido eléctrico, y el trabajador tuvo garantizadas las cinco sextas partes de su salario mensual cualquiera que fuera la jornada efectiva de trabajo. Las mismas industrias afectadas por el paro tuvieron que pagar inicialmente la tercera parte del subsidio, en el supuesto de que serían unas horas a recuperar por los trabajadores, pero la persistencia de la crisis convirtió en ilusoria esa claúsula, hasta que a principios de 1949 el gobierno pagó la totalidad del mismo.

La creación del subsidio de paro fue, a juicio de la ponencia, una medida necesaria y que mereció el aplauso general, pero sólo podía ser eficaz para remediar una situación circunstancial y de carácter transitorio. Al adquirir el subsidio un carácter permanente, resultó algo muy perjudicial para la economía del país. En un principio el subsidio permitió suplir la disminución del poder adquisitivo del salario, pero al desaparecer aquella posibilidad por el progresivo empeoramiento de la situación económica general, las fatales consecuencias de un paro prolongado se pusieron de manifiesto: «El trabajador perdió el estímulo del trabajo ya que llegó a la conclusión de que le resultaba más cómodo y más económico no trabajar, que hacerlo normalmente y percibir salarios (...)» ${ }^{21}$.

\section{Descenso del rendimiento de la mano de obra}

Al gran descenso de la producción motivado por las restricciones eléctricas, se unía el producido por el bajo rendimiento de la mano de obra. Según expone

\footnotetext{
20 Ponencia de 1949.

21 Ibid.
} 
la ponencia, en todas las industrias en las que después de un periodo de paro subsidiado (por la escasez de energía o por la falta de materia prima en el caso particular de la textil algodonera) se había restablecido, por un tiempo más o menos prolongado, la jornada normal de trabajo, el descontento del personal obrero había sido patente y manifiesto. El trabajo normal no resultaba remunerador a los obreros, dada la escasa diferencia entre jornal y subsidio; por lo que con diferentes motivos - por faltas voluntarias más o menos justificadas, enfermedad, etc. - no asistía al trabajo diario un alto porcentaje de la plantilla de cada industria. Las estadísticas de bajas por enfermedad venían de hecho registrando un aumento progresivo.

Por otra parte, en muchas industrias, en particular del sector textil, el incentivo en la remuneración del trabajo, el trabajo a destajo, que era la base de una producción normal, había dejado de ser eficaz por causa de ese sistema de pluses y subsidios. Hasta 1936 el trabajo a destajo significaba para los trabajadores textiles aproximadamente un incremento del 20 al $25 \%$ sobre el salario medio. Un incremento notable en la percepción semanal de los obreros activos que se traducía en un estímulo sólido y eficaz para el rendimiento del productor. En 1949, por el contrario, por altas que fueran las tarifas de destajo, su valor representaba siempre una proporción insignificante en el total del salario, ya que los subsidios, pluses y superpluses, suministros en especie, salario dominical y de días festivos, aumentos por antigüedad, plus de cargas familiares etc., eran cantidades fijas, independientes en absoluto del destajo y del rendimiento del trabajo. «Faltan estadísticas oficiales sobre este particular, pero las consultas efectuadas entre industriales textiles de reconocida solvencia, cifran ese descenso del rendimiento de la mano de obra entre el 30 y el $40 \%$ en relación con el año $1935 »^{22}$.

\section{Críticas a la política social}

Los industriales reconocen que la política social iniciada durante la guerra constituía uno de los más legítimos motivos de orgullo del régimen. Pero estiman que (...) «una política social de ese tipo es cara, y sólo una economía sana y floreciente podía soportarla. Por término medio, sólo los seguros sociales obligatorios representaban el $40 \%$ del importe de los salarios, y a ello debe añadirse el incremento por vacaciones, pagas extraordinarias, fiestas no recuperables, salario dominical, etc., etc. No es exagerado afirmar, pues, que el salario efectivo resulta incrementado en un $75 \%$ aproximadamente» ${ }^{23}$.

Los industriales consideran, así mismo, que la política social podría llegar a justificar, tal vez, repercusiones desfavorables en la economía nacional, pero son

22 Ibid.

23 Ibid.

Hispania, LXIII/3, núm. 215 (2003) 1057-1078 
muy críticos con algunos aspectos de aquélla, como «las numerosas disposiciones legales y oficiales que directa o indirectamente, contribuyen a la reducción de la jornada de trabajo y al descenso de la producción. El Decreto de 24 de julio de 1947 redujo a 7 horas y media la jornada efectiva de trabajo de las mujeres en las industrias a doble turno. Casi todas las reglamentaciones de Trabajo han elevado a diez o más los días de vacaciones retribuidas del personal obrero. El número de fiestas no recuperables ha aumentado asimismo, y la recuperación de las que tienen tal carácter en la provincia de Barcelona y para las industrias a doble turno ha quedado reducida a la mitad por orden de la Delegación de Trabajo de 13 de agosto de $1947^{24}$. Las citadas disposiciones significaban todas ellas una disminución de la jornada legal de trabajo, así como el descenso y encarecimiento de la producción.

Pero en este orden de cosas resultaba todavía más anti-económico, a juicio de la ponencia, el criterio acumulativo con el que se interpretaba la orden de 27 de julio de 1949 sobre los porcentajes de aumento de salario por antigüedad. Dicho criterio determinaba aumentos de salarios de hasta el $38 \%$ de su valor. Esa situación produciría problemas como la competencia ruinosa con las empresas de nueva creación. Éstas últimas tendrían la mano de obra un $38 \%$ más barata que las que llevasen años en funcionamiento. En segundo lugar, esa medida supondría una falta de estímulo al rendimiento para los trabajadores jóvenes, que por más que se esforzaran, nunca podrían alcanzar los salarios que, a ritmo lento de trabajo, obtenían los trabajadores mayores. Por último, se produciría una caída vertical y absoluta del régimen de trabajo a destajo, ya que éste no podría llegar a compensar nunca las diferencias que habían de suponer los aumentos por antigüedad.

\section{La falta de materias primas y el encarecimiento del mercado interior}

Por último, los industriales critican el problema de la falta de materias primas que había impuesto la disminución drástica del comercio exterior. La ponencia se refiere exclusivamente al algodón, por ser la materia prima textil de importación más característica, y la industria algodonera la más directamente afectada.

Después de 1945 una gran parte del algodón se importó a través de las llamadas Cuentas combinadas, es decir, con trueque de algodón en rama por manufacturado. Los empresarios textiles denuncian que con ello se había creado un círculo vicioso para el que no se vislumbraba una salida. El abastecimiento de artículos de algodón del mercado interior dependía de las posibilidades de exportación de las manufacturas, pero como la producción interna resultaba cara, muy por encima de los precios corrientes en el mercado internacional, se imponía la necesidad de primar la exportación. La orden de 24 de

24 Ibid. 
junio de 1949 había abordado decididamente esa necesidad con el consiguiente aumento del precio de los manufacturados en el mercado interior, y debido a la grave crisis económica general se iba reduciendo progresivamente la capacidad de absorción de ese mercado interior.

\section{Medidas que proponen los industriales textiles para resolver la crisis}

La realidad social exigía, según los industriales catalanes, medidas que lograsen un positivo aumento del valor adquisitivo de los salarios, mediante un suministro más elevado de artículos alimenticios y una distribución más eficaz de los mismos. Esto no parecía factible, en opinión de éstos, si previamente no se eliminaban las trabas que había creado la excesiva presión intervencionista, sin otro resultado que disminuir la producción agrícola y aumentar el mercado negro. Era indispensable además, impulsar, mediante una legislación social adecuada, el aumento del rendimiento de la mano de obra, para incrementar, mejorar y abaratar la producción nacional.

La realidad económica exigía en suma un decidido esfuerzo para el desarrollo de las fuentes de riqueza de la nación. Resolver urgentemente el problema de la producción eléctrica, que tenía prácticamente paralizada a la industria, impulsar el comercio exterior para lograr el coeficiente de importación de materias primas indispensables y arbitrar un capital que permitiera renovar el viejo utillaje agrícola e industrial, las comunicaciones y los transportes ${ }^{25}$.

\section{LA OPOSICIÓN POLÍTICA: LAS ELECCIONES MUNICIPALES DE 21 DE NO- VIEMBRE DE 1948 EN BARCELONA}

En el plano político, la situación de crisis se reflejó también en las elecciones municipales de noviembre de $1948^{26}$. Fueron éstas las primeras elecciones de regidores que se celebraban según el procedimiento de tercios arbitrado en la Ley de Bases de Régimen Local, aprobada tres años antes.

Aunque la ley de Bases configuraba la vida municipal como representación por tercios corporativos, los gobernadores continuaron controlando la composición de los ayuntamientos. En el caso de los tercios sindical y de entidades, los electores tenían que votar a los candidatos propuestos por el gobernador. La abstención y el desinterés se explicaban por cuanto ese tipo de procedimiento no pasaba de ser un «reparto de premios» entre los grupos más adictos al fran-

25 Ibid

26 Sobre la política municipal véase MARÍN i CORBERA, Martí, Els ayuntaments franquistes a Catalunya: política i administració municipal, 1938-1979, Lérida, Pagès, 2000.

Hispania, LXIII/3, núm. 215 (2003) 1057-1078 
quismo. Pero, sobre todo en Barcelona, la organización del Movimiento se encontraba en plena crisis política ${ }^{27}$, y había cierto miedo a la opinión pública.

Desde finales de 1942, y ante la previsible victoria de los aliados, el movimiento monárquico comenzó a reavivarse y algunos sectores de la Lliga Regionalista adquirieron un notable protagonismo. Figuras catalanas de tradición monárquica, como el barón de Viver, el conde de Montseny o Santiago Nadal, y otras vinculadas a la Lliga, como Ventosa i Calvell, Abadal o de Carreras, apoyaron el Manifiesto de don Juan de 1945 en Lausana.

Una vez concluida la guerra mundial, en unos momentos de animadversión política contra el régimen, el objetivo de las municipales de 1948 fue mantener, de cara al exterior, la ficción de unas elecciones. Aunque, al parecer, algunos «gubernamentales" se pronunciaron sobre lo poco oportuno de esta convocatoria, destacó la nueva beligerancia concedida a la Falange ${ }^{28}$. Según el monárquico Santiago $\mathrm{Nadal}^{29}$, la intromisión del partido en circunstancias tan críticas debía relacionarse con otros hechos, como la designación del ministro de Justicia, Raimundo Fernández Cuesta, como secretario del mismo. Una hábil medida, según aquél, para tener representada oficialmente a la Secretaría del Movimiento en el Gobierno, sin que ello implicara el nombramiento de un ministro especial, como había sucedido hasta la destitución de Arrese.

La nueva actitud profalangista de Franco obedecía, según Nadal, al clásico sistema de balanceo para contentar a todos. Sin olvidar tampoco su costumbre de hacer callar, mediante un cargo oficioso, a quien insinuase criterio político propio o tendencias disidentes. En el caso concreto de las municipales de Barcelona, dos de los candidatos designados por el Consejo Provincial de Falange eran falangistas "puros», disgustados con el Gobierno desde la entrevista del Azor. «Es ocioso decir que estos falangistas «puros» no han vuelto a mencionar para nada los errores que a su juicio cometía el régimen» 30 .

Destinadas a cubrir los ocho puestos del primer tercio de concejales del Ayuntamiento, las elecciones de 1948 se caracterizaron por dos rasgos bien definidos: en primer lugar, por la extraordinaria combatividad gubernativa, dado el propósito rotundo de sacar por abrumadora mayoría a todos los candi-

27 DE RIQUER, Borja, El franquismo y la transició...p. 69.

28 Sobre este tema véase CHUECA, Ricardo, El fascismo en los comienzos del régimen de Franco. Un estudio sobre FET-JONS, Madrid, CSIC, 1983 y SÁNCHEZ RECIO, Glicerio, Los cuadros políticos intermedios del régimen franquista, 1936-1959. Diversidad de origen e identidad de intereses, Alicante, Instituto de Cultura Juan Gil-Albert, 1996, y en el ámbito catalán, THOMAS, Joan $\mathrm{M}^{\mathrm{a}}$, Falange, guerra civil, franquisme. FET y de las JONS de Barcelona en els primers anys del règim franquista, Barcelona, Abadía de Montserrat, 1992. También las memorias de FARRERAS, F., Gosar no mentir. Memòries, Barcelona, Edicions 62, 1994.

29 Informe de Santiago Nadal, comentarista de la revista Destino y miembro destacado del grupo monárquico catalán, a la Secretaría Política de Juan de Borbón, 26 de noviembre de 1948. Archivo conde de Fontanar, Archivo Histórico, Universidad de Navarra. Sin paginar. Nadal informaba puntualmente al conde de Fontanar sobre la situación política de Cataluña.

30 Ibid. 
datos oficiales. En segundo lugar, por el rechazo del electorado, manifestado en una gran abstención que alcanzó el $75 \%{ }^{31}$.

\section{Preparación de las candidaturas}

Las etapas de preparación de las elecciones fueron muy laboriosas, endureciéndose los procedimientos de coerción a medida que se acercaba la fecha de su celebración. Desde el primer momento (a las dos semanas de publicarse en la prensa la ley electoral) el gobernador civil de Barcelona, Eduardo Baeza Alegría ${ }^{32}$, en respuesta a una consulta particular manifestó abiertamente: «Estas elecciones se harán en mi despacho, porque yo no creo en la democracia»33.

Diversos representantes políticos (personalidades o miembros de grupos más o menos organizados que deseaban participar en la acción administrativa, para la cual parecían haber sido convocadas las elecciones) se entrevistaron privadamente con el gobernador, con el fin de asesorarse sobre las garantías que gubernativamente se otorgarían a los candidatos para desarrollar su labor de propaganda. Todos fueron advertidos de que «no sería tolerada propaganda oral por medios públicos de difusión, permitiéndose únicamente la propaganda escrita a domicilio, con textos previamente sometidos a la aprobación de la censura» ${ }^{34}$. Ante tal situación, confirmada después por el ministro de la Gobernación, las fuerzas políticas de oposición al Movimiento decidieron abstenerse totalmente de concurrir a la supuesta consulta electoral. ${ }^{35}$

La actitud monárquica fue vacilante; oscilaba, de hecho, entre una postura de franca oposición y otra que tendía a las negociaciones con las autoridades, que llegaba a adquirir, en ciertos momentos, un matiz colaboracionista. La propuesta que gubernativamente se les formuló —incluir algunos nombres de escaso prestigio en la lista oficial- fue finalmente rechazada (los monárquicos tenían, según Nadal, posibilidades de hacer figurar en la candidatura nombres que movilizaran a la opinión).

Tampoco cuajó el entendimiento de los monárquicos con la Lliga. Nadal explica que los dirigentes de esta antigua formación política consideraban que, de formarse la candidatura de oposición, debían corresponderles seis o siete puestos frente a uno o dos de los monárquicos. Una proporción que los monárquicos estimaban, no sólo que no se correspondía con la situación real de fuer-

31 Ibid.

32 Médico de profesión, Eduardo Baeza era muy criticado por los sectores falangistas, que le consideraban una especie de enemigo interno.

33 Informe citado de 26 de noviembre.

34 Informe de Santiago Nadal a Francisco Carvajal, de 30 de noviembre de 1948, Archivo conde de Fontanar, Archivo Histórico, Universidad de Navarra. Sin paginar.

35 COLOMER, Josep María, AINAUD, Josep María y RiQuer, Borja de, Els anys del franquisme, Barcelona, Dopesa, 1978. 
zas, sino que debía ser justamente al contrario. La Lliga Regionalista conservaba indudablemente un fuerte núcleo de simpatizantes, pero en las circunstancias de entonces — tan distintas de las de 1931 o 36 - no podían aspirar, de ningún modo, a la supremacía absoluta sobre los monárquicos ${ }^{36}$.

\section{Eliminación previa de candidatos}

En cuanto a los grupos franquistas, el informe monárquico explica los procedimientos irregulares con que se jugó para la eliminación previa de candidatos. Como la ley electoral permitía la presentación libre de candidatos cumpliendo unas formalidades administrativas bastante prolijas, diversas personas, obrando independientemente, acudieron a la Junta Municipal del Censo para ser inscritas. Hubo 44 aspirantes a la proclamación previa de sus candidaturas. De estos 44 sólo fueron admitidos 26 . Unos se retiraron voluntariamente, otros quedaron descartados por el incumplimiento de algún requisito en la documentación electoral. Todos los que tenían carnet de Falange fueron instados a retirarse, aunque en aquel momento ya no militaran personalmente como falangistas, ni fuesen falangistas sus convicciones ideológicas. El argumento que se adujo fue «que habiendo designado ya el Comité Provincial del Partido a los candidatos que debían representarle no podía tolerarse la presencia de otros miembros del Partido en calidad de «franco-tiradores» ${ }^{37}$.

Con otros aspirantes se emplearon, según el informe monárquico, métodos distintos, tales como amenazas, cargos que podrían perder, etc. Las personas restantes sufrieron una criba posterior por un procedimiento sumario: el día de la convocatoria para recoger sus credenciales de candidato se les hizo saber "que les había sido admitida ya la renuncia». Al pretender alegar algo «se les arrojó literalmente a empellones del edificio» ${ }^{38}$. De esta forma quedaron eliminadas cuantas personas podían representar, por su relativo prestigio, un peligro para los nombres que formaban la lista oficial, quedando junto a éstos únicamente un grupo de candidatos de escaso relieve.

Estos últimos se agruparon en forma de una candidatura alternativa en la que figuraban «los ultracatólicos de tipo más bien clerical, pero sin contactos con el régimen: una especie de grupo «democristiano» con algún elemento catalanista y otros de matiz tradicionalista» ${ }^{39}$. En conjunto, tampoco tenían, según los

\footnotetext{
36 No se conoce bien la actitud de los sectores catalanistas que apoyaron al franquismo durante la guerra y que luego se desengañaron por la política que siguió el régimen. Por ahora, el estudio más completo es el de Borja de RIQUeR, $L$ 'últim Cambó. La dreta catalanista davant la Guerra Civil $i$ el primer franquisme, 1936-1947, Vic, Eumo, 1996.

37 Informe citado de 30 de noviembre.

38 Ibid.

39 Ibid
} 
monárquicos, mucho más prestigio ciudadano que los ocho candidatos oficiales. Les faltaba claridad de objetivos políticos y gente políticamente preparada.

Desde el primer momento, el gobernador entró en campaña contra esa candidatura en la que figuraban nombres como García Nieto, Cuffí, Cañadell y Modolell Barba. Así, hablando con los periodistas, el gobernador civil afirmó que la candidatura oficial era «el Credo». Preguntado sobre qué ocurriría si la gente votaba a la otra candidatura, respondió: «da lo mismo; el Credo saldrá triunfante» ${ }^{40}$.

\section{La manipulación electoral}

Los procedimientos de manipulación electoral se explican de forma detallada en el informe. Así, se indica que se trató desde el principio de preparar actas y mesas con personas adictas al régimen, pero que no fue infrecuente el caso de que, debido al desconocimiento que los miembros del partido tenían del pueblo, salieran personas neutras para ocupar las mesas.

A los presidentes y adjuntos de mesas se les obligó a firmar actas en blanco antes del día de la elección, igual que se había hecho en julio de 1947. con el referéndum. A todos los presidentes se les dieron por escrito instrucciones reservadas en las que se enumeraban toda clase de inconvenientes a poner contra los interventores y apoderados de la candidatura de oposición. En ellas se especificaba "que si el candidato viniese acompañado de notario (cosa no muy probable) el presidente enlazará inmediatamente, dilatando la actuación notarial con buenas formas, hasta que se presente persona competente» ${ }^{41}$. Además se les indicó con toda claridad que debían favorecer la candidatura oficial, y que contaban con la fuerza pública. En una reunión que tuvo lugar en el Gobierno Civil entre Baeza y los interventores gubernativos, aquél les dijo textualmente refiriéndose al cómputo de votos: «recuerden ustedes que dos y dos son veintidós» ${ }^{42}$.

La prensa y la radio se pusieron al servicio de la candidatura oficial, prohibiéndose a los directores de los medios que dieran curso a anuncios de la oposición, ni siquiera previo pago. Se les impidió, además, la difusión de propaganda a domicilio, negándoles la Junta del Censo a los opositores la entrega de las listas de votantes, que por imperativo legal debían serles facilitadas si así lo solicitaban ${ }^{43}$.

Por último, el gobernador ordenó al decano del Colegio de Abogados, Trabal, que indicara a los notarios sobre la conveniencia de ausentarse el día de las elecciones. Trabal cumplió dócilmente esta orden, que, sin embargo, desatendieron algunos de ellos.

\footnotetext{
40 Ibid.

41 Ibid.

42 Ibid.

43 Ibid.
} 
Pese a las citadas medidas preventivas, se tuvo que utilizar la violencia para neutralizar a la candidatura de oposición. Según expone el informe monárquico, esta candidatura tenía prevista la presencia de interventores suyos en cierto número de colegios, pero no se les permitió el ejercicio de sus funciones. Se les disuadió con diversos pretextos, y si el argumento no convencía, grupos de jóvenes del partido oficial expulsaban a los interventores recalcitrantes. Algunos interventores fueron detenidos por la policía y con ellos los presidentes de mesa que trataron de atenerse estrictamente a la ley y se opusieron a estas u otras tropelías. Además, esos grupos de jóvenes desconectaron los teléfonos de los dos centros electorales montados en casa de García Nieto, en la Ronda de San Pedro $n^{\circ} 29$, y en la Plaza Urquinaona, $n^{\circ} 5$.

\section{Los resultados electorales}

Por último, señala el informe que en el momento de las elecciones, y al hacerse patente la enorme abstención, se introdujeron en las urnas numerosas papeletas de la candidatura oficial. El promedio de votantes se acercó al 29\%, a pesar de que numerosos funcionarios necesitaban el certificado de haber votado. Las autoridadés proclamaron que había votado del 70 al $80 \%$ del Censo, pero después mantuvieron un prudente silencio sobre las cifras. Se prohibió además a los periódicos de Barcelona recordar que el censo de cabezas de familia ascendía a casi 300.000 , y no se facilitaron datos por distritos para que los ciudadanos no pudieran juzgar la falsedad con la que se les informaba sobre unos hechos que ellos mismos habían comprobado ${ }^{44}$.

En el análisis que Santiago Nadal hace de las elecciones reconoce la falta de coordinación de los monárquicos, pero estima que se equivocaron al no presentar candidatura alguna: «Hubiese causado cierto revuelo en los medios políticos y en la opinión pública. Si en vísperas del día 21 la hubiesen retirado, con la justa alegación de falta de garantías, nadie podría haberles negado que la abstención del electorado constituía una victoria particular suya» ${ }^{45}$. Nadal opina que más que aspirar a sacar concejales, habrían forzado aún más al gobierno a manipular las elecciones y la situación se habría reflejado también ante la opinión pública exterior. Pero, en todo caso, reconoce que no se presentó candidatura porque faltaban personas adictas para actuar de interventores, apoderados, etc.

Por otra parte, el periodista catalán no ve «qué peligro hubiera corrido el régimen de salir triunfante algún candidato ultra-católico o alguna persona más o menos apolítica que se creyó de buena fe el mito de la eficacia en la gestión municipal» ${ }^{46}$. En su opinión, queda patente la voluntad del régimen de no ampliar sus bases.

44 Idid.
45 Ibid.
46 Ibid. 
En resumen, las dificultades para sacar adelante la candidatura oficial y la enorme abstención electoral demostraban la oposición ciudadana a la política del régimen. Con todo, a pesar de la debilidad del partido oficial y de la falta de interés por ampliar la base social del régimen, esas fuerzas de oposición carecían de cohesión y de planteamientos políticos claramente definidos.

\section{El viaje de Franco a Cataluña}

La oposición general a la política del régimen se manifestó también en el viaje de Franco a Barcelona en junio de 1949. La gravedad de la situación económica y los problemas socio-laborales de Cataluña determinaron al jefe del Estado a trasladarse personalmente a Barcelona. A pesar de que los ministros conocían el malestar reinante en la ciudad ${ }^{47}$ y desaconsejaban el viaje, el jefe del Estado decidió estudiar la situación de cerca y permaneció en ella durante la primera quincena de junio.

La prensa recibió, según informes de la oposición monárquica, consignas de titular el viaje como de estudio y de contacto con los problemas regionales. «(...) Se desistió, por precaución, de organizar grandes actos o concentraciones sindicales o del Partido y las medidas policiales fueron impresionantes, diez veces mayores que las adoptadas durante un viaje anterior en junio de $1947 »^{48}$.

Franco, según refleja el informe, comprobó con sorpresa que «la cuestión catalana» tenía su origen en la política económica del régimen y reaccionó con dureza. $\mathrm{Al}$ parecer, había supuesto hasta entonces que el problema catalán se debía a un fenómeno de orden interno, de falta de cooperación entre el sector bancario, el comercial y el productor. No cabía en su mentalidad que el propio gobierno estuviera implicado en una crisis causada por el desbarajuste legislativo y la política económica ${ }^{49}$.

Según el informe, el caudillo quedó desagradablemente impresionado por las críticas a la política del régimen, y, más concretamente, a la línea seguida por el ministro de Industria, Juan Antonio Suanzes. No obstante, reaccionó inmediatamente y les dijo a los catalanes que debían resolver la crisis por sí solos, y que tendrían que producir tres veces más. No recibirían ayuda del exterior y el Estado tampoco podría prestarla.

En contra de la imagen oficial que ofrecía la prensa, se explica que en las calles de la ciudad condal se constatase la frialdad del pueblo. La gente trabajadora

47 Discurso pronunciado con motivo de la visita a la Delegación Provincial de Barcelona, Diario de Barcelona, 9 de junio de 1949.

48 Informe de la Secretaría de Juan de Borbón de 16 de junio de 1949 sobre el viaje de Franco a Barcelona. Archivo conde de Fontanar, Archivo Histórico, Universidad de Navarra. Sin paginar. La fuente de la información se obtuvo a través del Ministerio de Asuntos Exteriores.

49 Ibid. 
no pasaba por alto que la ración de pan era de 125 gramos y de pésima calidad, dado el bache que se atravesaba en el abastecimiento del trigo argentino.

Las citadas fuentes monárquicas refieren que la oposición a Franco se constató en diversos momentos de la visita. El 10 de junio el caudillo inauguró la Feria de Muestras de Montjuich: «A lo largo de la Gran Vía apenas se apiñaba una doble fila de mujeres y niños deseosos de contemplar a la Guardia Monta$\mathrm{da}$; tímidos aplausos anunciaron el paso del coche de Franco» ${ }^{50}$.

En la Escuela Industrial se hizo una pequeña concentración de aprendices obreros, a los que se llevó en camiones y se les metió en el patio con algunas demostraciones de fuerza. Allí, los falangistas les distribuyeron propaganda impresa que los aprendices quemaron con una audacia sorprendente. En cuanto Franco terminó su breve discurso se produjo una rápida desbandada. «La Falange sigue revolucionaria. Elementos de la Secretaría del partido y el jefe de Juventudes, Elola, intentaron atraer al sindicalismo, mediante ofrecimientos de altos cargos, a algunos antiguos miembros de la CNT. Las conversaciones no tuvieron éxito porque los cenetistas se negaban como condición previa a ingresar en Falange. La Falange da la impresión de querer ampliar la base sabiendo que la masa obrera no les sigue» ${ }^{51}$.

En la función de gala del Liceo, que se celebró por la noche, se apreció igualmente, dice el informe, un notable retraimiento de la nobleza y de la alta burguesía. Muchos barceloneses de representación habrían preferido ausentarse de la ciudad para pasar el fin de semana en el campo.

A pesar de que el ministro Suanzes afirmó, en declaraciones a la prensa local, que los problemas sociales se habían solucionado gracias a la política del gobierno: "paro agudo no ha existido en absoluto, y esto gracias a las medidas de aspecto social con que el estado ha afrontado el problema y a la colaboración también de las empresas», haciendo notar, además, que los suministros extraordinarios de carburantes mejoraron notablemente la situación ${ }^{52}$, el viaje de Franco reflejó el descontento general.

\section{LA HUELGA GENERAL DE MARZO DE 1951}

En los años cuarenta, las huelgas y manifestaciones obreras habían tenido un tono bastante espontáneo, para protestar por la carestía de la vida y demandar un aumento de los salarios. Desde 1947, evaporada la esperanza de un rápido final de la dictadura, se abrirá una segunda etapa en la que las huelgas comienzan a adquirir un carácter mucho más organizado y político. A medida que el malestar aumentaba, comenzó la infiltración de miembros de organiza-

\footnotetext{
so Ibid.

s1 Ibid.

\$2 Diario de Barcelona, 8 de junio 1949.
} 
ciones obreras clandestinas como «enlaces sindicales». La táctica del PCE y del PSUC consistió en romper el aislamiento a través de la utilización de cargos electivos de la OSE 53 .

En marzo de 1951, la tensión acumulada a lo largo de la década anterior, desencadenó en Barcelona una huelga que pondría de manifiesto el descontento general frente al régimen. Los periódicos no dieron el más mínimo informe sobre lo que se considera uno de los episodios fundamentales de la oposición ${ }^{54}$.

La idea de organizar la huelga general, que paralizó importantes empresas de Barcelona y su entorno a mediados de marzo de 1951, partió de una asamblea de enlaces sindicales en el local del Consejo Nacional de la Organización Sindical de la Vía Layetana, en la que los dirigentes de la OSE fueron desbordados y perdieron el control del acto.

Según explican las fuentes monárquicas, la protesta tuvo un carácter popular, masivo y semiespontáneo, que desconcertó a las autoridades de Barcelona. Participaron en la campaña los grupos antifranquistas, sectores "católicos» 55 (de la Asociación Católica Nacional de Propagandistas) e incluso falangistas disconformes con el gobernador civil y jefe del partido ${ }^{56}$; pero su seguimiento masivo demuestra, en opinión de las citadas fuentes, un profundo malestar general, y el escaso peligro que presentaba una acción de esas características.

Desde hacía varios días el descontento general se había concretado en la Compañía de Tranvías, cuyo mal servicio era atribuido principalmente a la pésima administración municipal. En estas circunstancias, una crónica de La Vanguardia en Madrid dio cuenta de que la tarifa en esa capital era de 0,40 pesetas. Un hecho que provocó indignados comentarios, ya que la tarifa en Barcelona era de 0,70 pesetas y llegaba a costar en algunos días festivos cerca de 1 peseta. Unas octavillas, repartidas por la calle y remitidas por correo a domicilios de entidades y a algunas personas particulares, incitaban a realizar una «huelga de viajeros»: a dejar de utilizar los tranvías el 1 de marzo ${ }^{57}$.

La gente en abrumadora mayoría mostró inmediatamente su conformidad con la petición de rebajar la tarifa. Pero ya desde unos días antes de esa fecha, en concreto desde el viernes 23 , los estudiantes comenzaron a mostrar nerviosismo, no entrando en algunas clases, abucheando a la policía, etc. ${ }^{58}$. Los días 27 y 28 el asunto alcanzó proporciones de verdadero motín. Por toda la ciudad

\footnotetext{
S3 MOLINERO, Carme e YSÁS, Père, Productores disciplinados y minorías subversivas. Clase obrera y conflictividad laboral en la España franquista, Madrid, Siglo XXI, 1998.

54 Carta de Santiago Nadal al conde de Fontanar, Barcelona 2 de marzo de 1951. Archivo conde de Fontanar, Archivo Histórico, Universidad de Navarra.

s5 Véase sobre esta participación RAMOS, Gemma, op.cit. p. 209.

s6 FABRÉ J.; HUERTAS, J. M., y RIBAS, A., Vint anys de resistència catalana (1939-1959), Barcelona, La Magrana, 1978, p. 219.

57 FANÉs, Félix, La vaga de tranvies de 1951, Barcelona, Laia, 1977.

58 COLOMER i CALSINA, Josep María, Els estudiants de Barcelona sota el franquisme, vol. 1 Barcelona, Curial, 1987.
} 
grupos de estudiantes se lanzaron sobre los tranvías, rompiendo prácticamente los cristales de todo el servicio.

La policía, tanto en el edificio central de la Universidad, como en la Facultad de Medicina, lanzó cargas violentas que se sucedieron a lo largo de todo el día, incluso a las horas de máxima afluencia de público en las Ramblas y en la céntrica calle de Pelayo. Numerosos petardos colocados en las vías del tranvía o arrojados por los estudiantes completaron el cuadro, que «ciertamente, recordaba tiempos pasados» ${ }^{59}$.

«El 1 de marzo el público, de manera rotundamente unánime, con una unanimidad nunca vista en estos casos, atendió la consigna de no utilizar los tranvías. Los obreros que trabajan lejos de sus casas se llevaron la comida para no tener que regresar a ellas a pie y los que no eran obreros tomaron también sus medidas para no tener que usar de los servicios de la compañía. Era un espectáculo imponente ver los coches ocupados únicamente por los empleados y por una o dos parejas de la Policía Armada. Los comentarios del público eran elocuentes y demostraban que la protesta sobrepasaba con mucho la simple cuestión de las tarifas tranviarias» ${ }^{60}$.

El día 2, el espectáculo se reprodujo íntegramente, si bien la compañía redujo ya a una cantidad meramente simbólica la circulación de sus coches. Se volvieron a suceder los incidentes, cargas etc., «mostrando la policía un nerviosismo evidente y las autoridades una desorientación total» ${ }^{61}$.

Un intento de manifestación, numerosísima y espontánea, que surgió de entre el público hacia la una de la tarde, en la esquina de la Plaza de Cataluña y las Ramblas fue duramente reprimido por la fuerza pública. Las detenciones sumaron varios centenares. Ante la gravedad de la situación las entidades económicas decidieron el 5 de marzo, con la autorización del ministro de Obras Públicas, que el billete de tranvía volviera a costar 50 cts. Josep María Llopis, presidente de la Cámara de Comercio y portavoz ante el gobernador civil de la plataforma creada en el curso de la huelga de tranvías para tratar de resolverla de manera conciliatoria, definía a aquélla como «actitud de disconformidad, en su origen, y planteamiento inicial, espontánea y cívica» ${ }^{62}$.

«Lo más grave fue la incapacidad de las autoridades para ponerles coto con más habilidad que violencia. De hecho, fue impresionante la unanimidad, que se calificó como el hecho más extraordinario de la historia político-social de la ciudad, de que toda una ciudad de millón y medio de habitantes se lanzara como un solo hombre a obedecer una consigna no se sabe lanzada por quién,

59 Sergio VILAR, en su Historia del antifranquismo, 1939-1975, Barcelona, Plaza y Janés, 1984, reconoce también, a pesar de su carácter en gran parte espontáneo, la politización de la situación a partir del día 23 de febrero.

60 Carta citada de 2 de marzo de 1951.

61 Ibid.

62 La Vanguardia, 6 de marzo de 1951. 
ya que el alcance de las hojas convocatorias fue al parecer limitadísimo" ${ }^{63}$. Se trató de una colaboración unánime y entusiasta «nacida de un hondísimo y grave disgusto contra toda la política del régimen» ${ }^{64}$.

Según comunica Nadal, no se sabía si esa semana saldría a la calle Destino6s, porque se negaba a publicar una nota reprobatoria de la actitud del público. «Un artículo muy matizado, condenando las violencias, pero atribuyendo la responsabilidad profunda del motivo de descontento al Ayuntamiento y a la Compañía de Tranvías, quedó desautorizado por la censura» ${ }^{66}$.

El éxito del boicot desembocó en una huelga general que tuvo lugar el 12 de marzo, apoyada por todas las instancias sociales incluyendo a los sectores tradicionalmente contrarrevolucionarios. La convocatoria partía esta vez de la Confederación Nacional de Sindicatos. Los enlaces antifranquistas consiguen controlar la asamblea y convocar esa protesta contra la carestía de la vida y para conseguir la libertad de los detenidos con motivo del boicot ${ }^{67}$. La situación revelaba el éxito de nuevas formas de oposición basadas en una acción de masas en las que se aprovechaban las instancias legales del régimen y se incorporaban nuevos sectores como estudiantes, católicos y falangistas.

La huelga, que se extendió desde el cinturón industrial hasta el centro de la ciudad, se saldó con un muerto y varios heridos. Las principales autoridades fueron destituidas.

En resumen, a diferencia de lo que ocurrió en Madrid y en algunas otras capitales de provincia, donde las primeras huelgas ${ }^{68}$ respondieron a una protesta por la carestía de la vida, la de Barcelona tuvo un carácter más claramente político y de oposición al régimen. ${ }^{69}$ Así, la huelga de Madrid se limitó a la abstención obrera de los medios de transporte, sin que hubiera, como en Barcelona, solidaridad entre las diversas clases sociales. Sin embargo, al decir de los observadores, impresionaba la disciplina que sin excepción demostró la clase trabajadora llegando y marchando a pie de su trabajo.

63 Carta citada de 2 de marzo de 1951.

64 Ibid.

65 Sobre la citada revista véase Cabellos y Minguez, P. y Pérez Vallverdú, E., "Destino. Política de unidad (1936-46). Tres aspectes del inici d'una transformació obligada», Els Marges, núm. 37, mayo de 1987, y Gell, C. y HuerTAS, J. M., Les tres vides de Destino, Barcelona, Diputación de Barcelona / Colegio de Periodistas de Cataluña, 1990. La revista pasó desde el falangismo de los primeros años a ser aliadófila y monárquica.

66 La revista se refería en un editorial del 10 de marzo, al mal servicio que prestaban los tranvías. Carta citada de 2 de marzo de 1951.

67 RAMOS RAMOS, Gemma, «Tranvías y conflictividad social en Barcelona (marzo de 1951): actitudes políticas y sociales de una huelga mítica», en Historia Contemporánea, n 5, 1991, pp. 203-217.

68 VÁzQUez de Prada, Mercedes y RUIz Garrido, Rosario, «Oposición carlista y franquismo en Navarra: los contrafueros de 1952 y 1954", en VV.AA., II Encuentro de Investigadores del Franquismo, Alicante, Instituto Juan Gil-Albert, 1995.

69 Destino aludía en un artículo de 24 de marzo al delicado momento político en el que tomaba posesión el nuevo Gobernador Civil de Barcelona, Felipe Acedo. 
Por primera vez, informan los monárquicos, Franco no pudo asomarse al balcón de la Plaza de Oriente en el desfile del 1 de abril de ese año ante la falta de público que lo justificara ${ }^{70}$. La incapacidad del régimen para garantizar los abastecimientos más elementales y para condenar públicamente el desenfreno en los gastos públicos, así como la corrupción de gran parte de las jerarquías gubernativas provocaba ya, según aquéllos, la ira popular ${ }^{71}$.

La explosión de descontento popular que demuestra la huelga de 1951 en una de las zonas claves para el desarrollo industrial del país, acabará de poner de manifiesto la gravedad de la crisis de los años finales de los cuarenta y la necesidad de reorientar el rumbo general del régimen.

\section{CONCLUSIONES}

Los documentos utilizados aportan datos significativos sobre la intensa crisis socioeconómica y política que afectó a Cataluña en los años finales de la década de los cuarenta y sobre las primeras críticas que se producen de forma abierta a la política económica y social del régimen.

En el informe de la Industria de Barcelona, los empresarios textiles analizan las causas del conflicto sociolaboral y exponen las medidas que se deberían aplicar para resolverlo.

En primer lugar plantean que el alza desorbitada de los precios y la insuficiencia del racionamiento hacen subir la presión de los trabajadores, al borde de la miseria, en demanda de salarios más altos.

Afirman que, a las restricciones eléctricas, cada vez más frecuentes, a la falta de materias primas y al colapso del mercado exterior, se añade el fuerte descenso del mercado interior provocado por la caída del poder adquisitivo y el encarecimiento de la producción.

Atribuyen el aumento de los costes de producción al descenso del rendimiento de la mano de obra, desmotivada por la política de ayudas y subvenciones del régimen a los trabajadores.

Critican también la decisión tomada por el gobierno, a partir de 1949, de primar la exportación para paliar el problema de los altos precios y conseguir a cambio materias primas. A su juicio, esa política genera un círculo vicioso, ya que la prima a la exportación encarece los precios en el mercado interior de unas manufacturas que no pueden ser absorbidas por falta de poder adquisitivo de los salarios.

70 Carta de Ramón Sierra Bustamante a Juan de Borbón, Madrid 6 de mayo de 1951. Archivo conde de Fontanar, Archivo Histórico, Universidad de Navarra.

71 Conversación del conde de Fontanar con el conde de Montellano, mayo de 1951. Archivo conde de Fontanar, Archivo Histórico, Universidad de Navarra. 
Finalmente, proponen como soluciones el impulso del rendimiento de la mano de obra, mediante una política social adecuada para abaratar la producción, y una liberalización económica que permita resolver el problema de la falta de energía y de la escasez de materias primas, y renovar el utillaje industrial y los medios de transporte.

En el plano político, las fuentes monárquicas recogen las manifestaciones de oposición durante el desarrollo de las primeras elecciones locales celebradas en noviembre de 1948 , con un detallado relato sobre la manipulación electoral y el frío recibimiento que se hizo a Franco en su viaje a Cataluña.

En las elecciones, se ponen claramente de manifiesto la enorme abstención y el retraimiento que mostró la población de Barcelona, la crisis existente dentro de la propia Falange y la falta de organización y unidad de criterios por parte de las fuerzas de oposición de la derecha.

En síntesis, se viene a decir que el triunfo de la candidatura oficial, con muchas dificultades, indicaba la beligerancia que se dio a Falange, a pesar de la crisis que atravesaba, pero también la debilidad de las fuerzas de la derecha. Tanto los monárquicos, como los antiguos miembros de la Lliga, y los grupos católicos carecían de planteamientos políticos claramente definidos, de figuras preparadas, y se encontraban desunidos.

Respecto al viaje de Franco a Cataluña, en 1949, concluyen que fue motivado por su alarma ante la grave "crisis catalana», y que aunque en él comprobó con sorpresa que la crisis era debida a la política económica de su Gobierno, Franco insistió en exigir un mayor esfuerzo a los catalanes, que deberían resolver la crisis por sí solos, sin ayuda ni del exterior ni del Estado.

Finalmente, la documentación consultada refleja el carácter masivo de la huelga de 1951 en Barcelona, que supuso la primera movilización general contra el régimen. La huelga desbordó los motivos económicos adquiriendo un carácter de protesta política y marcó el inicio de una nueva etapa en la política franquista, que deberá reorientar la política económica y ampliar la base social. 